\title{
How Do Culturally-Derived Values Affect Teachers' Perception Of The Value Of On-Line ELT Courses: The Case Of Hong Kong
}

Icy Lui, Hong Kong Institute of Education, Hong Kong

\begin{abstract}
This paper describes the program characteristics of the on-line courses, analyses how culturally-derived values influence teachers' conception of their roles in the learning situation, and aims at describing the classroom pedagogical implication in terms of the future role of teachers in order to make the most out of the on-line courses that the School offers for students.
\end{abstract}

\section{A. INTRODUCTION}

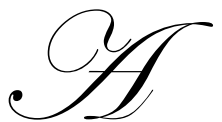

$\mathrm{s}$ an international city, Hong Kong has been a meeting place for the East and West for many years. In many aspects of life, Hong Kong is very westernized. Yet when it comes to the views, values and beliefs of how education works, teachers are still very Asian-oriented. This paper reports on what motivates teachers in Hong Kong, how they themselves see their work and how their previous experience shapes their teaching pedagogy. In particular, this paper focuses on teachers' perception and priorities on the delivery of English on-line Courses run by the School of Continuing and Profession Education of the Hong Kong Institute of Education in 2006.

The first part of the paper describes the program characteristics of the on-line courses, the second part analyses how culturally-derived values influence teachers' conception of their roles in the learning situation. They include teacher conception of their roles as teachers and of their professional responsibilities, teachers' goals of teaching, possible factors (such as their personal experiences, the expectation of their students) that influence teachers' practice; the place of face-to-face communication in ELT, teacher preparation and attitudes towards the usefulness of on-line materials, and the function of learning English via the computers and its place in the curriculum. The last part of this report aims at describing the classroom pedagogical implication in terms of the future role of teachers in order to make the most out of the on-line courses that the School offers for students.

\section{B. THE USE OF ON-LINE ENGLISH COURSES FOR CONTINUING AND PROFESSIONAL EDUCATION}

The continuing growth and development of continuing professional education in Hong Kong as a result of the transformation of our economic structure, globalization and our increasing ties with China has picked up greater momentum in recent years. There are an ever-increasing number of students who are busy individuals themselves and have to juggle their time among work, play, family and continuing education. In the light of this situation, distance learning, on-line courses and web-based learning have emerged as a powerful force in helping course-providers to deliver various programs to meet the needs of these students. With the advent of the internet, web-based courses can deliver education over a distance and it has enabled more people to have a variety of choices on specialized courses that they want to study. This alternative format for delivering courses also provides students with more flexibility in organizing their study. They can choose the time they want to access the materials and they are no longer by the location or venue of the course-providers. 
In line with the current development, the School of Continuing and Professional Education has offered a series of on-line courses to students. This part describes the program characteristics of the English Language Courses offered. These courses include Examination Preparation Courses e.g. IELTS preparation and English Enhancement Programs for our Associate Degree students. The purposes of these courses aim at offering extra-help for students with their English Language skills to pass public examinations for entry to University/Higher Education Courses or to achieve the level of English standard that would enable them to pursue higher education courses in English and for work purposes. The mode of delivery of these courses is $20 \%$ contact hours, $80 \%$ on line study. In general, it takes students about 100 hours to complete the exercises and participate in the discussions of the courses, plus about another 60 hours to write up assignments. A minimum of 10-15 weeks are given to students to complete all work. Class contact hours were in the range of 30-36 hours on average. However, some groups (students who are preparing for examinations) may take up an intensive mode that lasts for just 3-4 weeks. Students enrolled in these courses were mostly our full-time, part-time students from our Associate Degree Courses and some working adults who need to get good grades in IELTS to secure their jobs or promotion prospects at work.

\section{B.1. Features of the On-line ELT Courses}

Features include basic components like the following:

\section{Components for Students:}

- $\quad$ Access to unit content (Activities and Exercises; journal articles, book chapters and other printed materials)

- Announcements Page

- Course calendar

- $\quad$ Email Network

- Discussion Board

- Digital Dropbox

\section{Component for Tutors:}

$\begin{array}{ll}\text { - } & \text { Assessment Manager } \\ \text { - } & \text { Online Grade book } \\ \text { - } & \text { Course Calendar } \\ \text { - } & \text { Tracked Accesses of students } \\ & \text { Course Statistics }\end{array}$

Information available for Course Statistics:

- Total Number of Accesses per Area

- Number of Accesses over Time

- User Accesses per Hour of the Day

- User Accesses per Day of the Week

- Total Accesses by User

\section{HOW DOES CULTURALLY-DERIVED VALUES INFLUENCE TEACHERS' AND STUDENTS' CONCEPTION OF THEIR ROLES IN THE LEARNING SITUATION}

One of the aims of this study is to investigate how culturally derived values guide teachers in employing certain teaching styles/techniques that help them achieve their teaching objectives. Broadfoot (1994) pointed out that the professional profiles of teachers from different cultural backgrounds varied in terms of different notions of accountability and responsibility. The present study aimed at finding out Hong Kong teachers' views on the value of on-line courses, its place in the Language curriculum, their definition of their role as teachers, how their previous experience and training affect their attitudes, choice of teaching methods, and teachers' sense of professionalism etc. 
Put together, the data and findings will help reveal the role culture plays in defining the delivery format of on-line courses. Findings of this study were based on 10 tutors' reflection on an on-line questionnaire gauging the factors for success and obstacles of On-line ELT Courses offered by the School in the academic year 2006.

\section{1 Factors that Affect Teachers' Perception of Good Teaching}

In this part, we look at factors that help teachers define their roles and responsibilities and analyze whether they are conducive to the success of on-line ELT learning in Hong Kong. These factors include:

- Teachers' goals

- Teachers' conceptions of their roles

- Definitions of professional responsibility and accountability

- Views and values on classroom practices. Possible factors (such as their personal experiences, their students, their colleagues and their own reading and independent study) that influence their teaching styles and preference

Teaching has never been an easy job. Researchers are aware that teaching is a creative, often intuitive response of an individual to a diverse range of external pressures and requirements. Thus, in seeking to understand the way different teachers individually or collectively approach their work, we need to take into account a number of factors. They include the personality of the teacher, her family background, her professional experience including her training and subject discipline, and above all, her professional perspectives i.e. her expectations, habits, goals in education that may be mediated by an institutional setting that is shared with her immediate colleagues. Some researchers have started to explore the significance of teachers' thinking and how their view of professionalism informs their classroom actions and is in turn related to the context of their lives as a whole. As Ball and Goodson (1985, p.8) put it:

Alongside the recognition of the complexity of the teacher's tasks and the importance of the interplay between initiating and responsive acts in the classroom, greater attention has been directed to teachers as human beings, as rounded social actors with their own problems and perspectives, making careers, struggling to achieve their ideals or just struggling to "survive".

What defines teachers' goals of education and priorities are fundamentally social in character. As Acker (1987, p14) pointed out:

The content of what is to be learned; the conditions under which the encounter takes place; the characteristics of the parties concerned all reflect the social and cultural arrangements of a given society in a particular era...

Educational practices need to be conceptualised as part of a particular social context and culture. Teachers' professional values are a reflection of what is treasured in their social context. Every education system has its own identity. There are social and cultural messages that define the meaning of a particular educational activity in different societies and they will in turn influence the interactive process between teacher and student, student and text, teacher and policy (Broadfoot, 1993). In order to understand the impact of teachers' pedagogy on students' outcomes, it is necessary to consider the ways in which particular national traditions and social settings can influence how the task of teaching is seen. As Acker (1987, p.20) puts it:

Teaching can be seen as a task or a role, performed with others; as a profession or career; as an activity shaped by historical, social and economic forces... Thus the work of the primary teacher, however concentrated on day-to-day roles and relationships, cannot escape the influence of social, economic and political change. These factors by no means determine her every move, but provide the context and constraints within which she makes her choices and finds her satisfaction. 
To help explain teachers' classroom actions and decisions, we have to probe into their minds and find out what factors are behind their actions. As Floden point out, research on teachers' beliefs has been seen as a valuable complement to traditional approaches to the study of teaching. The information obtained from such studies clarifies the nature of teachers' knowledge and belief systems, their views as to what constitutes good teaching, and their views of the systems in which they work and their roles within it: such beliefs serve a background to much of the "culture" of teaching (Floden, 1990).

\section{2 Teachers' Perspectives on the Value of On-line ELT Courses}

Results from the end-of-course questionnaire on teachers revealed teachers' conception of the value of on-line English courses, the factors for success as well as obstacles posed on On-line ELT Courses in Hong Kong. It was found out that culturally derived values exert a large influence in affecting teachers' interpretation of their professional values and definitions of good educational practices.

\section{C.2.1 Teachers' goals and conceptions of their roles:}

Responses indicated that teachers were very much influenced by their previous experience and aimed at improving students' English standards by giving them as much hands-on practice as possible. In general, they felt the obligation to guide students through the maze of exercises in the on-line courses and provide students with guidelines they need with personal input and face to face interaction. They feel that it is important for students to be "duly introduced" into the practice with "human touch" instead of following instructions on the computer screen. They define their professional responsibilities as "mentors" who steer students through their learning course and to "guide them by holding onto their hands".

\section{C.2. 2 Definitions of professional responsibility and accountability:}

Traditional classroom practice in Hong Kong has the teacher taking up a formidable presence in the classroom. Teachers are used to taking up the figure of authority that follows the work and progress of students closely. Teachers also pride themselves on their intimate relationship with their students which they establish in the classroom through constantly giving the class directions and instructions and gauging their feedback in person.

In the new setup of cyber learning, teachers' roles and responsibilities are different from the traditional classroom setting. Teachers are expected to take up the role of facilitators. They are expected to interact with students from a distance: through emails or on-line platform or chat-groups. Feedback from teachers' evaluation revealed that as the courses progress and students got more engaged in on-line discussions and participate more actively, teachers found it very time-consuming to read all the postings, respond to emails and give feedback/opinions on discussions. They also feel stressed out when they are unable to reply or respond as expected in order to keep the level of high interactivity and reflection. In a way, they had the feeling that their sense of professionalism was not duly recognized as their major task had now been shifted to monitoring students' progress by giving students' feedback on their assignments and discussion on line. Moreover, they found it hard to sustain "learner independence" by encouraging participants to finish on-line exercises without the students' physical presence and reporting in person. They believe that students would be more accountable for their work when they are required to account for their learning to the teacher in person.

\section{2.3 Views and values on classroom practices:}

Results from the questionnaire indicated that one of the biggest obstacles facing teachers while implementing on-line courses seems to be their background. Without the experience of being an on-line learner himself/herself, the teacher finds himself/herself overwhelmed by the anxiety about using the technology. Also, difference in student's individual computer skills cause tensions. Teachers are perplexed by how much time should be spent during contact hours using computers and they found it difficult to decide what materials to cover during contact sessions. They are also uncertain how best to implement the content in a lively way without the teacher 
taking the lead.

While teachers admitted that they were aware of the importance of creating a 'reflective' community of learners by encouraging active involvement/interaction by initiating them to on-line discussion via the Discussion Board; they found it difficult to achieve this aim with an on-line course. They believe that it is most effective to get students to participate actively and reflect critically when they are physically present in the classroom, where motivation comes from the atmosphere the teacher created and the rapport established in the classroom. At the same time, they think that without knowing each other, it is hard to set the scene in cyberspace for a safe and trusting environment for students to share ideas openly on line. In sum, teachers think that there are things that were best done in the classroom setting and in the face to face mode, which they have had lots of successful experience. In other words, teachers found it hard to develop a sense of belonging in the participants using an on-line course, and they have reservations on how they could engage participants in reflective and critical thinking via cyberspace without setting up good personal relationship foundation with students. They stressed the importance of knowing students in person, being able to be near them, see their eyes and know their faces, which are all important elements in building up good classroom rapport, which is conducive to positive and effective learning experiences.

\section{FUTURE ROLES OF WEB-BASED ELT}

It is foreseeable integrating technology in traditional ELT classroom will take up an increasing important role in the future. As more students with very busy personal schedule would enroll in various ELT courses like examination preparation course, enhancement course and work place English course, the trend is that ELT courses may be fully delivered on-line very soon. However, its success and expansion will be based on whether teachers are ready to exploit the interactivity that comes with on-line learning (tutors able to monitor students' progress, give encouragement and provide support for learning via cyberspace). From the observations in the present research, it was found out that teachers in Hong Kong are influenced by their tradition and their concept of good teaching.Their professional values and definitions of good educational practices predispose them to take up a personal approach to teaching that put emphasis on the importance of face-to-face interaction with their students. They suggested that the minimum contact hours with students should not be less than $40 \%$ of the course duration. They stressed that this would enhance students' motivation and clear a lot of obstacles for learning. At the moment, they think that on-line learning can only be treated as a kind of supplementary or enhancement method to complement a course taught in class. It can not replace traditional teaching in the classroom.

In order to position web-based materials in the English Language curriculum, it is paramount that teacher education courses that address the needs of teachers be designed: these involve the reinterpretation of the teachers' responsibility from that of an informer to that of a facilitator, the nature of the learning process, how to best implement teaching content on-line and what to cover during contact hours. Last but not the least, education administrators need to pay due recognition to teachers' effort and time spent on monitoring students' progress on-line so teachers have enough time to invest in establishing relationship with students and make effective and full use of the interactivity that the on-line platform offers for teaching and learning.

\section{REFERENCES}

1. Acker, S. (1987). Primary school teaching as an occupation. In S. Delamont (Ed.) The Primary School Teacher. Lewes: Falmer Press.

2. Alexander, R. J. (2000). Culture and Pedagogy: International Comparisons in Primary Education. Blackwell Publishers Ltd. UK.

3. $\quad$ Ball, S. and Goodson, I. (Eds.) (1985). Teacher's Lives and Careers. Lewes: Falmer Press.

4. $\quad$ Biggs, J. B. \& Watkins, D. A., (Eds). (1996). The Chinese Learner: Cultural, Psychological, and Contextual Influences. Australian Council for Educational Research, Melbourne; Hong Kong University.

5. Braine, G. (1997). Beyond word-processing: Networked computers in ESL writing classes. Computers and Composition, 14(1), 45-58. 
6. Broadfoot, P \& Osborn, M, with Gilly, M. and Brucher, A. (1993). Perceptions of Teaching: Primary School Teachers in England and France. London: Cassell.

7. Chambless, J. and Chambless, M. (1994). The impact of instructional technology on reading/writing skills of 2nd grade students. Reading Improvement, 31(3), 151-155.

8. Clark, W. (1996). Effects of a computer-assisted instruction program on aboriginal student achievement. (ERIC Document Reproduction Service No. ED400777.)

9. Dimmock, C. (2000). Designing the Learning Centered School: A cross-cultural perspective. London and New York: Falmer Press.

10. Floden, R. E. (1990). Two views of the role of research on teacher thinking. Issue paper (National Center for Research on Teacher Learning (U.S.); pp.90-94.

11. Huang, S. (1998). Differences in the nature of discussion between peer response sessions conducted on networked computers and those conducted in the traditional face-to-face situation. (ERIC Document Reproduction Service No. ED423686.)

12. Huang, S. (1999). Internet assisting EFL writing learning: From learners' perspective. (ERIC Document Reproduction Service No. ED429460.)

13. Izzo, J. (1996). An analysis of computer workstation and handwriting use by ESP students. (ERIC Document Reproduction Service No. ED394295.)

14. Jackiewicz. G. (1995). The effect of computer-based instruction on writing at the elementary school level. (ERIC Document Reproduction Service No. ED380802.)

15. Jacoby, S. (1993). Assisting secondary limited English proficient students through the implementation of computer-assisted language learning. (ERIC Document Reproduction Service No. ED364101.)

16. Jannasch-Pennell, A.; DiGangi, S.; Yu, A.; Andrews, S; and Babb, J. (1999). Impact of instructional grouping on navigation and student learning in a Web-based learning environment. (ERIC Document Reproduction Service No. ED436156.)

17. Pennington, M. (1993). Exploring the potential of word processing for non-native writers. Computers and the Humanities, 27(3), 149-63.

18. Richards, C. (1996). The impact of the Internet on teaching and learning in education as perceived by teachers, library media specialists and students. (ERIC Document Reproduction Service No. ED41094.)

19. Roskams, T. (1998). Collaborative interaction in networked writing classrooms: The student experience. (ERIC Document Reproduction Service No. ED424780.)

20. Snyder, I. (1993). The impact of computers on students' writing: A comparative study of the effects of pens and word processors on writing context, process and product. Australian Journal of Education, 37(1), 5-25.

21. Sullivan, N. and Pratt, E. (1996). A comparative study of two ESL writing environments: A computer-assisted classroom and a traditional oral classroom. System, 24(4), 491-501.

22. Yang, K. S. (1986). Chinese personality and its change. In M. H. Bond (Ed.) The Psychology of the Chinese People. (pp. 106-170). New York: OUP. 